\title{
Mesoscale engineering of photonic glass for tunable luminescence
}

\author{
Yongze Yu ${ }^{1,2}$, Zaijin Fang ${ }^{1,2}$, Chuansheng $\mathrm{Ma}^{3}$, Hiroyuki Inoue ${ }^{4}$, Guang Yang ${ }^{3}$, Shupei Zheng ${ }^{5,6}$, \\ Danping Chen ${ }^{5,6}$, Zhongmin Yang ${ }^{1,2}$, Atsunobu Masuno ${ }^{4}$, Jiri Orava ${ }^{7,8}$, Shifeng Zhou ${ }^{1,2}$ and Jianrong Qiu ${ }^{1,2}$
}

Control of the optical behavior of active materials through manipulation of their microstructure has led to the development of high-performance photonic devices with enhanced integration density, improved quantum efficiencies and controllable color output. However, the achievement of robust light-harvesting materials with tunable, broadband and flattened emission remains a long-standing goal owing to the limited inhomogeneous broadening in ordinary hosts. Here, we describe an effective strategy for the management of photon emission by manipulating the mesoscale heterogeneities in optically active materials. Importantly, this unique approach enables control of dopant-dopant and dopant-host interactions on the extended mesoscale. This allows the generation of intriguing optical phenomena such as a high activation ratio of the dopant (close to 100\%), dramatically inhomogeneous broadening (up to $480 \mathrm{~nm}$ ), notable emission enhancement and, moreover, simultaneously extension of the emission bandwidth and flattening of the spectral shape in glass and fiber. Our results highlight that the findings connect the understanding of and manipulation in the mesoscale realm to functional behavior on the macroscale, and the approach to manage the dopants based on mesoscale engineering may provide new opportunities for the construction of a robust fiber light source.

NPG Asia Materials (2016) 8, e318; doi:10.1038/am.2016.156; published online 14 October 2016

\section{INTRODUCTION}

Multicomponent glass fibers are considered the building blocks of the next-generation of fiber photonics because they hold promise for the realization of a compact light source in a wide spectral range, which can be used in advanced applications, such as high-capacity telecommunication and remote sensing and in the defense industry. ${ }^{1-3}$ The ultimate challenge in achieving these operational modes is to develop a glass fiber material capable of emitting in a wide wavelength range. A conventional approach, tuning the glass composition, can achieve emission bandwidths up to $100 \mathrm{~nm}$, but extending the bandwidth remains a challenging task. ${ }^{3,4}$ Another effective strategy for extending the luminescence spectral range is based on a multicorefiber design, in which cores, with a variety of rare-earth dopants, are physically arranged into a single fiber., ${ }^{5,6}$ Unfortunately, generating broadband flatline-shape emission has been achieved with limited success because of the discrete energy levels in rare-earth ions. ${ }^{7}$

From the traditional point of view, the structural origin of the spectral broadening is the site-to-site variation of dopants in a specific host matrix. ${ }^{8,9}$ The corresponding structural ordering in homogeneous glasses is strictly limited to a short-range order of $\sim 5 \AA .{ }^{10,11}$ In contrast, the dopant-host matrix and the dopant-dopant interactions are known to operate on a length scale of at least one order of magnitude larger than the short-range order in glass. ${ }^{12,13}$ It seems to be accepted now that supercooled liquids develop structural heterogeneities on cooling, which are preserved in the glass and can, for example, be the origin of an inhomogeneous response to thermal strain. ${ }^{14}$ Motivated by these significant clues, we recognize that functionality of doped photonic glasses manifests itself not only on the atomic or short-range order scales but also in the extended mesoscale. Here, we validate this hypothesis by providing a link between fundamental electron transition processes in a dopant and the mesoscale behavior of glass. We show that manipulating the mesoscale heterogeneities in a multiphase glass-ceramic fiber can result in significant inhomogeneous emission broadening beyond the $100 \mathrm{~nm}$ limit and, for the first time, in successful simultaneous extension of the emission bandwidth with a flattened spectral shape.

\footnotetext{
${ }^{1}$ State Key Laboratory of Luminescent Materials and Devices, Guangdong Engineering Technology Research and Development Center of Special Optical Fiber Materials and Devices, School of Materials Science and Engineering, South China University of Technology, Guangzhou, China; ${ }^{2}$ Guangdong Provincial Key Laboratory of Fiber Laser Materials and Applied Techniques, South China University of Technology, Guangzhou, China; ${ }^{3}$ Electronic Materials Research Laboratory, Key Laboratory of the Ministry of Education and International Center for Dielectric Research, Xi'an Jiaotong University, Xi'an, China; ${ }^{4}$ Institute of Industrial Science, The University of Tokyo, Tokyo, Japan; ${ }^{5}$ Key Laboratory of Materials for High Power Laser, Shanghai Institute of Optics and Fine Mechanics, Chinese Academy of Sciences, Shanghai, China; ${ }^{6}$ University of Chinese Academy of Sciences, Beijing, China; ${ }^{7}$ Department of Materials Science and Metallurgy, University of Cambridge, Cambridge, UK and ${ }^{8}$ WPI-Advanced Institute for Materials Research (WPI-AIMR), Tohoku University, Aoba-ku, Sendai, Japan

Correspondence: Professor S Zhou, State Key Laboratory of Luminescent Materials and Devices, Guangdong Engineering Technology Research and Development Center of Special Optical Fiber Materials and Devices, School of Materials Science and Engineering, South China University of Technology, Wushan RD., TianHe District, Guangzhou 510640, China.

E-mail: zhoushifeng@scut.edu.cn

Received 9 May 2016; revised 9 August 2016; accepted 13 August 2016
} 


\section{EXPERIMENTAL PROCEDURES}

\section{Materials}

The transparent multicomponent glass was designed and prepared based on a standard phase diagram and the glass-forming ability of an $\mathrm{LiTaO}_{3}-\mathrm{SiO}_{2}-\mathrm{Al}_{2} \mathrm{O}_{3}$ system. The optimized composition of the host glass was $\mathrm{Li}_{2} \mathrm{O} / \mathrm{Ta}_{2} \mathrm{O}_{5} / \mathrm{SiO}_{2} /$ $\mathrm{Al}_{2} \mathrm{O}_{3}=25.53 / 21.53 / 35.29 / 17.65$ (in mol.\%). NiO powder was used for $\mathrm{Ni}^{2+}$-doping at the level of 0.15 mol.\%. For a typical synthesis, $\sim 40 \mathrm{~g}$ of the raw oxide materials ( $99.99 \%$ in purity) was homogeneously mixed and melted in a corundum crucible at $1600^{\circ} \mathrm{C}$ for $90 \mathrm{~min}$ in air using an electric muffle furnace. The investigated glass system has a high propensity for devitrification. To avoid the crystallization of glass, we employed the melting-quenching method. The melt was poured onto a preheated stainless brass mold and pressed with another brass plate. This method can provide a rapid cooling rate. The thickness of the as-produced glass was $2 \mathrm{~mm}$, and the size of the glass after cutting was $10 \mathrm{~mm} \times 10 \mathrm{~mm}$. The thermal properties of the prepared glass were measured by calorimetry and were used in the heat-treatment procedure to obtain the glass-ceramic composite. The glass-ceramic composites, with high optical transparency, were obtained by isothermal annealing at $750{ }^{\circ} \mathrm{C}$, typically for $3 \mathrm{~h}$. All samples were polished to optical quality.

\section{Characterizations}

The glass-transition and crystallization temperatures were measured by differential thermal analysis using an STA449C Jupiter (Netzsch, Bavaria, Germany) instrument in an argon atmosphere at a heating rate of $10 \mathrm{~K} \mathrm{~min}^{-1}$. The X-ray diffraction was done using a D8 advance X-ray diffractometer (Bruker, Faellanden, Switzerland) equipped with $\mathrm{Cu} / \mathrm{K} \alpha$ radiation. Raman spectroscopy, using a Renishaw InVia spectrometer with a 532-nm laser source, was performed for structural studies. The transmission and absorption spectra were recorded using a Perkin-Elmer Lambda 900 UV/VIS/NIR spectrophotometer (Waltham, MA, USA). The excitation and photoluminescence spectra were measured using an FLS920 fluorescence spectrometer (Edinburgh Instrument Ltd., Edinburgh, UK) equipped with a xenon arc lamp (Xe900). The luminescence decay curves were recorded with a microsecond flash-lamp $(\mu \mathrm{F} 900)$. The microstructure in both the glass and the glass-ceramic composite was characterized by transmission electron microscopy (TEM) and scanning
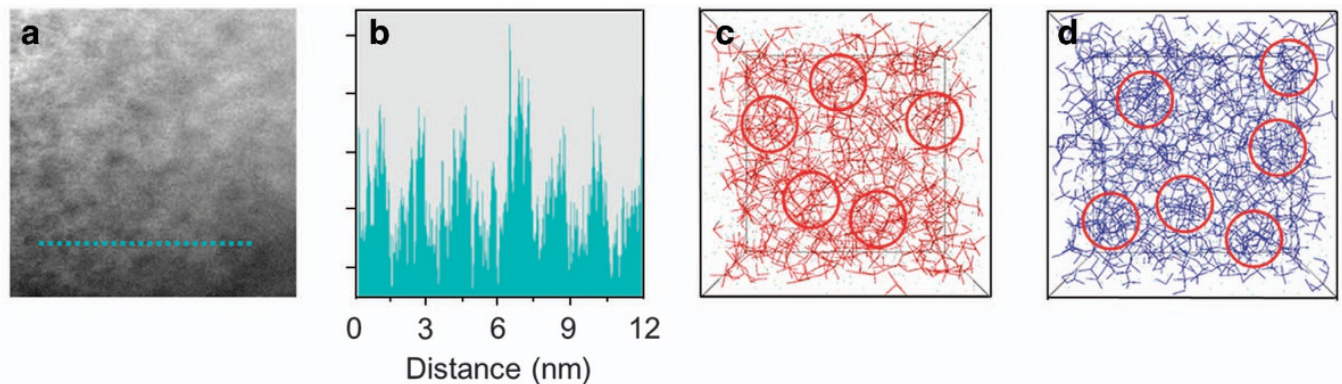

\section{Theoretical simulations}

Classical molecular dynamics simulations were performed to establish a structural model of the glass. To avoid atoms overlapping, the initial configurations were randomly generated with constraints between atom pairs. The time step for this simulation was set at $1 \mathrm{fs}$. The system was first equilibrated at $4000 \mathrm{~K}$ for 2000 time steps and then quenched to $293 \mathrm{~K}$ over 10000 time steps. A final relaxation, for 2000 time steps, was carried out at room temperature $(293 \mathrm{~K})$. The atomic configurations of the final step were used for preparation of the multiphase glass. More details about the simulations are shown in the Supplementary Materials.

\section{Fiber preparation}

A 'molten-core' fiber-drawing method was used for fabrication of a high optical quality fiber. ${ }^{15}$ The $\mathrm{Ni}^{2+}$-doped bulk glass with high homogeneity was shaped into a cylindrical rod with a diameter of $3 \mathrm{~mm}$ and a length of $55 \mathrm{~mm}$. To avoid the introduction of impurities into the fiber, the surface of the rod was carefully polished and washed by an acid (10\% hydrofluoric acid). The glass rod was inserted into a high-purity silica tube (99.999\%) with an inner
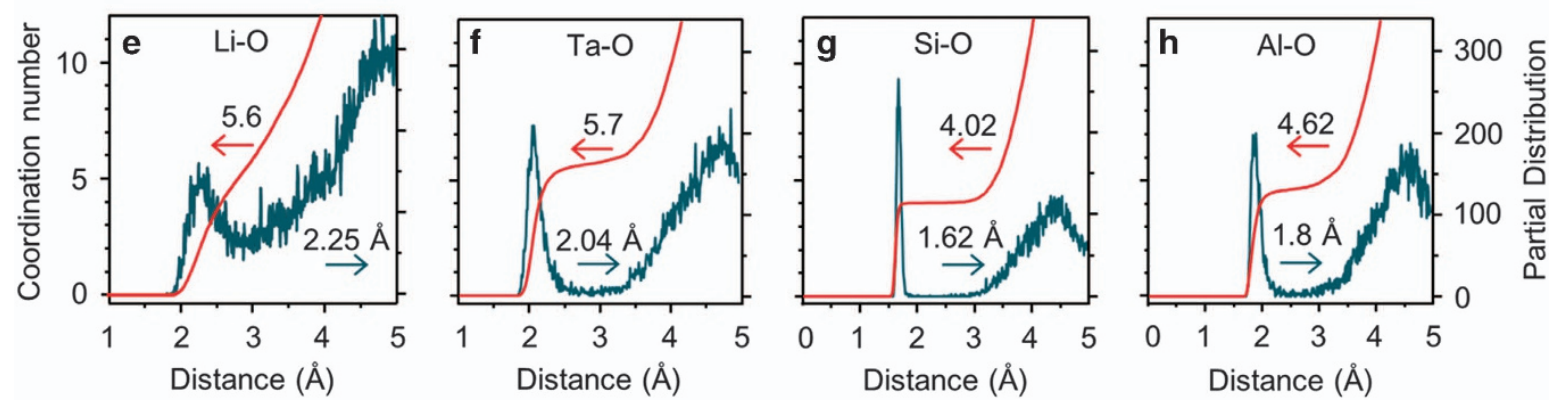

Figure 1 Mesoscale structure in the host $\mathrm{Li}_{2} \mathrm{O}-\mathrm{Ta}_{2} \mathrm{O}_{5}-\mathrm{Al}_{2} \mathrm{O}_{3}-\mathrm{SiO}_{2}$ glass. (a) HAADF-STEM glass micrograph shows the presence of mesoscale heterogeneities. (b) Line profile of the contrast from a. (c and d) MD simulations of the chemical bond distribution. The red and blue sticks represent Ta-O and Si/Al-O bonds, respectively. (e-h) The average coordination numbers and the partial distributions calculated from the structure model. The average coordination numbers of $\mathrm{Li}$ and $\mathrm{Ta}$ cations are 5.6 and 5.7, and their bonds distances were calculated to be 2.04 and $2.25 \AA$, which match well those in the LiTaO 3 crystal (Ta-0: $2.07 \AA$; Li-0: $2.29 \AA$ ). The average coordination numbers of Si and Al are 4.02 and 4.62 , and their bonds distances were calculated to be 1.62 and $1.8 \AA$. HAADF-STEM, high-angle annular dark-field scanning-transmission electron microscopy; MD, molecular dynamics. 
diameter of $3.1 \mathrm{~mm}$ and an outer diameter of $25 \mathrm{~mm}$, and the bottom of the tube was sealed with a silica rod.

The fiber-drawing process was performed at a temperature of $1950{ }^{\circ} \mathrm{C}$, at which the core precursor is melted and the silica cladding is sufficiently soft. To effectively reduce the inter-diffusion between the core and the cladding, a fast drawing speed is required. In a typical fiber-drawing process, the preform was fed into a furnace from the top with a speed of $2 \mathrm{~mm} \mathrm{~min}^{-1}$, and the fiber was pulled out from the bottom of the furnace with a speed of $1500 \mathrm{~mm} \mathrm{~min}^{-1}$.

The fiber was optically activated by annealing at $800^{\circ} \mathrm{C}$ for $20 \mathrm{~h}$, which is higher than that used for the glass sample. This is because the degrees of structural heterogeneity in the glass and the fiber samples are different due to the different cooling rate during the fabrication process. In addition, in fiber sample, the core material was covered with $\mathrm{SiO}_{2}$ cladding. In this case, the heattransfer process during the heat treatment is also different from the case of the glass sample.

\section{RESULTS AND DISCUSSION}

\section{Mesoscale structure in multicomponent host glass}

Origin of heterogeneity. A prototypical multicomponent $\mathrm{Li}_{2} \mathrm{O}-\mathrm{Ta}_{2} \mathrm{O}_{5}-$ $\mathrm{Al}_{2} \mathrm{O}_{3}-\mathrm{SiO}_{2}$ (LTAS) glass was designed and prepared based on the standard phase diagram and glass-forming properties of the $\mathrm{LiTaO}_{3}-$ $\mathrm{SiO}_{2}-\mathrm{Al}_{2} \mathrm{O}_{3}$ system (see Experimental procedures on details about the synthesis). This glass system was chosen because of its unique bonding features. $\mathrm{Ta}^{5+}$ ions with a high valence state, an intermediate field strength $(F=1.2)$ and a high Ta-O bond energy $\left(300-400 \mathrm{~kJ} \mathrm{~mol}^{-1}\right)$ show a high tendency to attract surrounding anions, resulting in local compositional/structural fluctuations in the glassy matrix. ${ }^{16}$ Light alkali $\mathrm{Li}^{+}$ions in the low valence state are highly mobile, have a low activation energy of diffusion $\left(\sim 67 \mathrm{~kJ} \mathrm{~mol}^{-1}\right)$ and facilitate structural rearrangements in the glass. ${ }^{16}$ The unique bonding features of $\mathrm{Ta}^{5+}$ and $\mathrm{Li}^{+}$ions in this study favor the so-called amorphous phase separation, potentially leading to the formation of a Ta- and Si/Al-rich glass phase. The initial localized heterogeneities are expected to be quenched from the melt, starting from a liquid-liquid phase separation.

To validate the hypothesis of the local heterogeneities present in the glassy $\mathrm{Li}_{2} \mathrm{O}-\mathrm{Ta}_{2} \mathrm{O}_{5}-\mathrm{Al}_{2} \mathrm{O}_{3}-\mathrm{SiO}_{2}$ system, the microstructure of LTAS was studied by high-angle annular dark-field STEM (Supplementary Figure S1). As shown in Figure 1a and b and Supplementary Figure S2, the STEM images show a typical pattern of regular heterogeneities on the mesoscale. The line profile, taken from Figure 1a, indicates periodic density fluctuations with an average characteristic length of $\sim 1.8 \mathrm{~nm}$ (Figure $1 \mathrm{~b}$ ).

In the high-angle annular dark-field STEM mode, the image intensity $(I)$ depends on the sample properties as follows: $I \propto \rho \times d \times Z^{1.5}$, where $\rho$ is the material density, $d$ is the TEM sample thickness and $Z$ is the atomic number. The relative atomic masses of $\mathrm{Ta}, \mathrm{Al}$ and $\mathrm{Si}$ are 180.9, 27.0 and 28.1, respectively. It is assumed that the brighter regions may correspond to areas containing more of the heavier elements, such as $\mathrm{Ta}$, while the darker regions are richer in the lighter elements, such as $\mathrm{Si}$ and $\mathrm{Al}$. The size of the heterogeneities is in
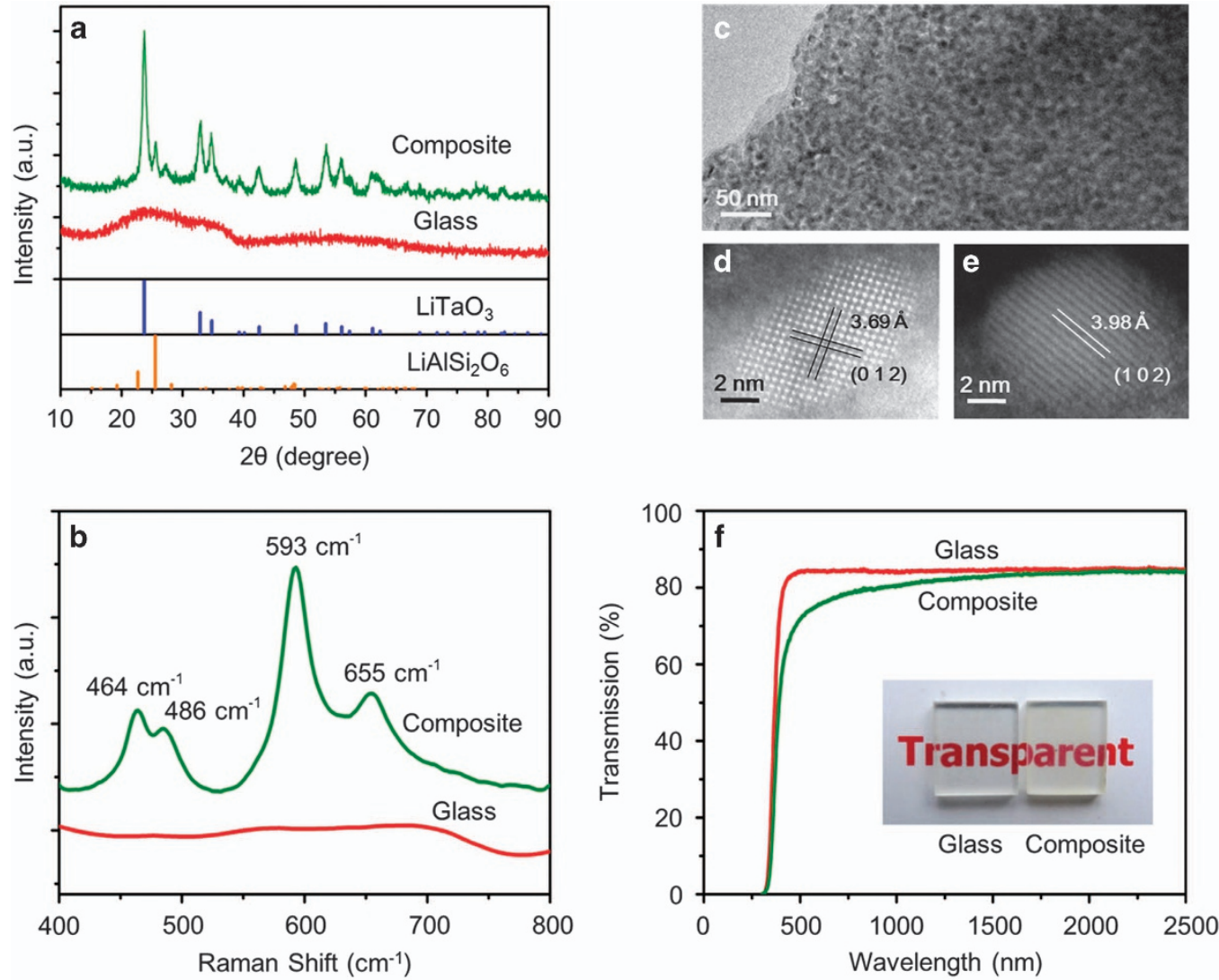

Figure 2 Structural characterization of the glass-ceramic composite. (a) XRD patterns of the glass and glass-ceramic composite. (b) Raman scattering spectra of the glass and glass-ceramic composite. (c) Bright-field TEM of the glass-ceramic composite. (d and e) Atomic-resolution HAADF-STEM images of, respectively, $\mathrm{LiTaO}_{3}$ and $\mathrm{LiAISi}_{2} \mathrm{O}_{6}$ nanoparticles present in the glass-ceramic composite. (f) Transmission spectra of the glass and glass-ceramic composite. The inset photographs show transparency of the glass (left) and glass-ceramic composite (right). HAADF-STEM, high-angle annular dark-field scanningtransmission electron microscopy; TEM, transmission electron microscopy; XRD, X-ray diffraction. 
the range of nanometers. The STEM images can illustrate the idea of $\left[\mathrm{TaO}_{x}\right]$ and $\left[\mathrm{Si} / \mathrm{AlO}_{x}\right]$ structural units demixing.

To shed more light on the origin of the observed heterogeneities, we performed molecular dynamics simulations to reveal the local coordination configuration and mesoscale ordering in the prototypical glass. Figure $1 \mathrm{c}$ and $\mathrm{d}$ show the distribution of $\mathrm{Ta}-\mathrm{O}$ and $\mathrm{Si} / \mathrm{Al}-\mathrm{O}$ bonds, represented by the red and blue sticks, respectively. Local separation between $\left[\mathrm{TaO}_{x}\right]$ and $\left[\mathrm{Si} / \mathrm{AlO}_{x}\right]$ units can be observed, as highlighted by the red circles (Figure 1c and d). Statistical analysis of the cation abundance ratio is presented in Supplementary Figure S3. In all these cases, the cation abundance ratio deviates from the average value in the regions with the reduced scale, representing local chemical heterogeneities. The study of the coordination features of the glass network former shows that the local heterogeneities can mainly be assigned to the existence of two coordination units, $\left[\mathrm{TaO}_{6}\right]$ and $\left[\mathrm{Si} / \mathrm{AlO}_{4}\right]$ (Figure 1e-h). The presence of heterogeneities in the glass was further tested for varying cooling rates, $3.7 \times 10^{12}, 7.4 \times 10^{12}$ and $3.7 \times 10^{13} \mathrm{~K} \mathrm{~s}^{-1}$, in molecular dynamics simulations (Supplementary Figure S4). In the limits of molecular dynamics cooling rates, a negligible influence of the cooling rate on the coordination configurations and the mesoscale architecture of the prototypical glass was observed.
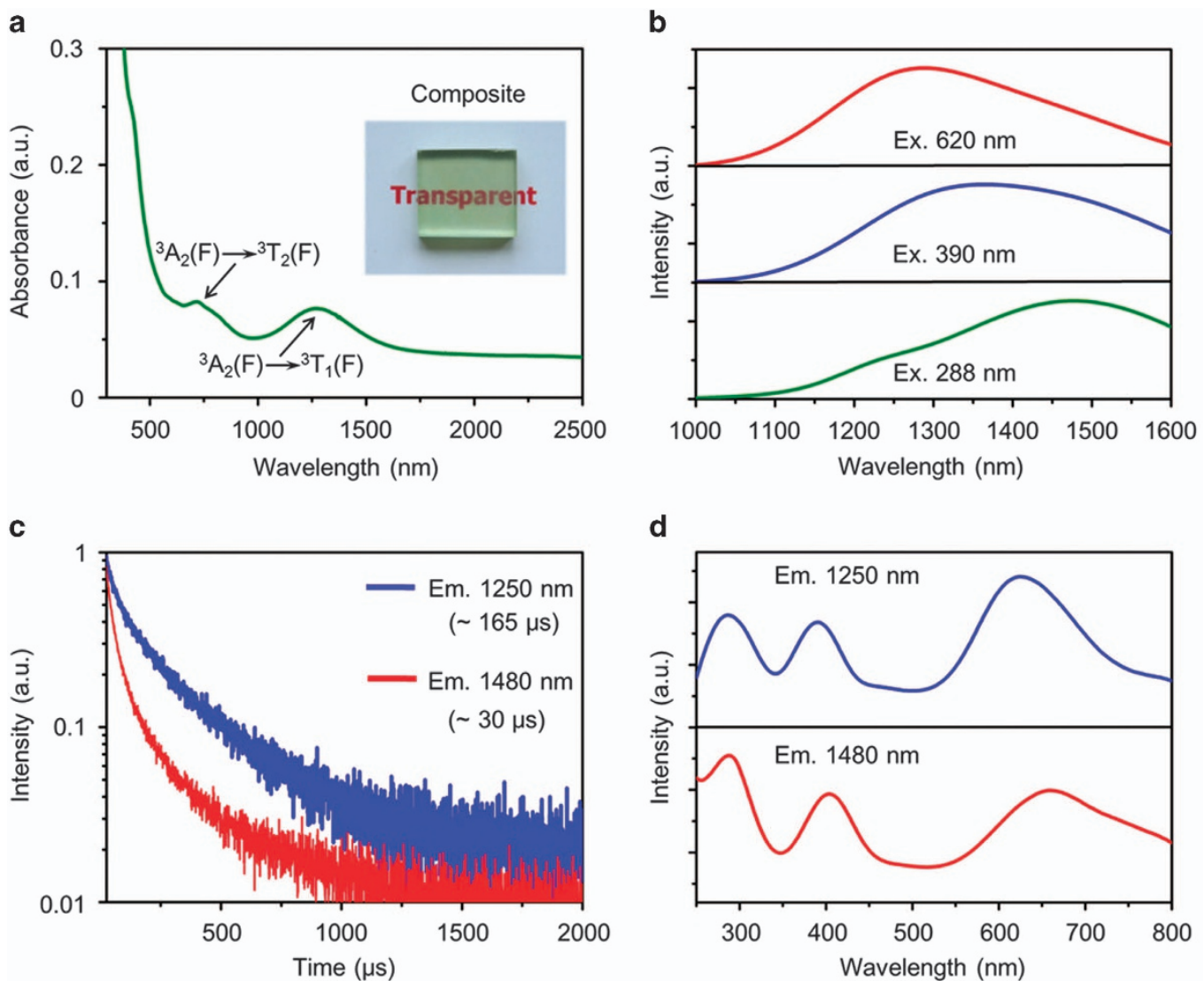

d

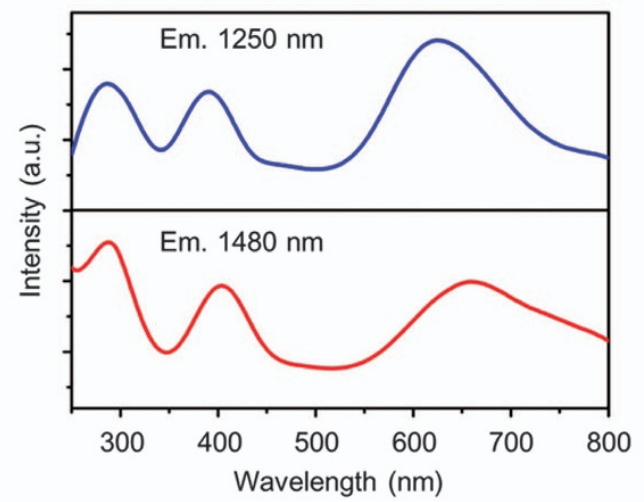

e
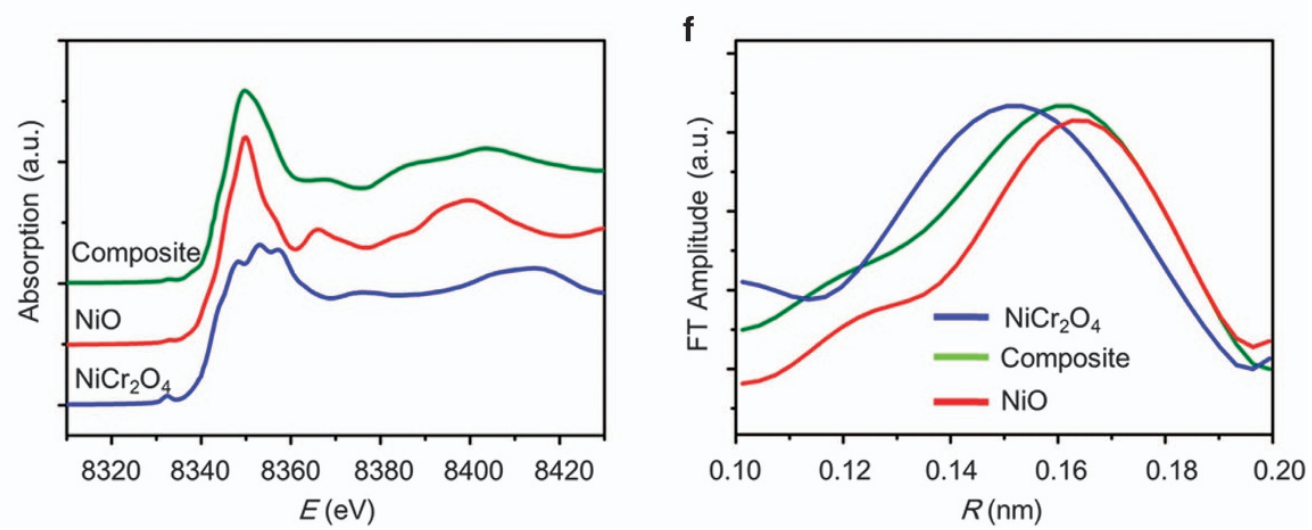

Figure 3 Optical properties of the $\mathrm{Ni}^{2+}$-doped glass-ceramic composite. (a) Absorption spectra and a glass-ceramic composite photograph, in the inset, are shown. (b) NIR luminescence excited at $\lambda=288,390$ and $620 \mathrm{~nm}$. (c) Decay curves of the NIR emission bands with the central emission wavelength at $\lambda=1250$ and $1480 \mathrm{~nm}$. (d) Photoluminescence excitation spectra of the NIR emission bands with the central wavelength at $\lambda=1250$ and 1480 . (e) XANES spectra of the $\mathrm{Ni}$ K-edge in the glass-ceramic composite, $\mathrm{NiO}$ and $\mathrm{NiCr}_{2} \mathrm{O}_{4}$. (f) $\mathrm{Ni}-\mathrm{Ni}$ partial distribution functions of the glass-ceramic composite, $\mathrm{NiO}$ and $\mathrm{NiCr}_{2} \mathrm{O}_{4}$. NIR, near-infrared; XANES, X-ray absorption near-edge structure. 
Multiphase glass-ceramic composite. The existence of mesoscale heterogeneities inside the glass can further be exploited in the development of multiphase glass-ceramic composite materials because the nucleation and crystal growth can be greatly affected by structural heterogeneities. On the one hand, the nucleation barriers are largely overcome by the structural heterogeneities where Ta- or Si/Al-rich regions form critical supersaturation domains. ${ }^{17}$ On the other hand, the local heterogeneities bear some similarities to the structure of the nucleating crystals, which can decrease the energy required to achieve the crystal growth. ${ }^{18}$ The LTAS glass was annealed for $3 \mathrm{~h}$ at $750{ }^{\circ} \mathrm{C}$, which is slightly above its glass-transition temperature of $T_{\mathrm{g}}=700^{\circ} \mathrm{C}$, but well below the crystallization temperature of $800^{\circ} \mathrm{C}$ (Supplementary Figure S5). At this temperature, the crystallization of glass occurs at a moderate rate. As a result, the size of nanocrystals can be well controlled by tuning the heat-treatment parameters, and a glass-ceramic composite with a high transparency can be achieved. The X-ray powder diffraction pattern of the annealed glass (Figure 2a) shows fingerprint peaks that can be indexed to the $\mathrm{LiTaO}_{3}$ and $\mathrm{LiAlSi}_{2} \mathrm{O}_{6}$ crystalline phases. The Raman scattering spectrum (Figure 2b) shows intensive peaks that are consistent with the vibrational modes of crystalline $\mathrm{LiTaO}_{3}$ and $\mathrm{LiAlSi}_{2} \mathrm{O}_{6} \cdot{ }^{19,20}$ The band at $\approx 464 \mathrm{~cm}^{-1}$ (E mode) can be assigned to Ta-O bending, and the bands at $\approx 593 \mathrm{~cm}^{-1}\left(\mathrm{~A}_{1}\right.$ mode) and $\approx 655 \mathrm{~cm}^{-1}$ (E mode) originate from Ta-O stretching. ${ }^{19}$ The band at $\approx 486 \mathrm{~cm}^{-1}$ can be assigned to a stretching mode of $\mathrm{T}-\mathrm{O}-\mathrm{T}$, where $\mathrm{T}$ represent $\mathrm{Si}$ or $\mathrm{Al}$ in the network..$^{20}$

In contrast, the as-prepared LTAS glass exhibits broad 'amorphous' halo peaks in both X-ray diffraction and Raman scattering data, indicating its glassy nature. Bright-field TEM micrographs (Figure $2 \mathrm{c}$ and Supplementary Figure S6) show the presence of dense crystalline nanoparticles, with average diameters of $\sim 5 \mathrm{~nm}$, embedded in the glassy LTAS matrix. Atomic-resolution high-angle annular dark-field STEM images, shown in Figure 2c-e, reveal a single-crystalline nature of the two typical particles, and the measured lattice fringes with $d$-spacings of 3.69 and $3.98 \AA$ are in good agreement with the lattice spacing of the (012) plane of $\mathrm{LiTaO}_{3}$

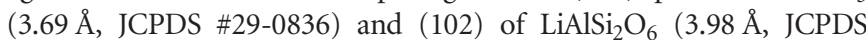
\#35-0797), respectively.

Importantly, the prepared glass-ceramic composite shows a high transparency in both the visible and the near-infrared (NIR) spectral regions (Figure 2f). The high transparency of the composite is primarily attributed to the uniformly dispersed nanocrystals within the glassy matrix.

The newly prepared nanocrystalline glass-ceramic composite, when optically activated by a proper dopant, $\mathrm{Ni}^{2+}$ ions in this study (see Materials in Experimental procedures), can become a novel multiphase photonic material, which is the main focus of the following sections.
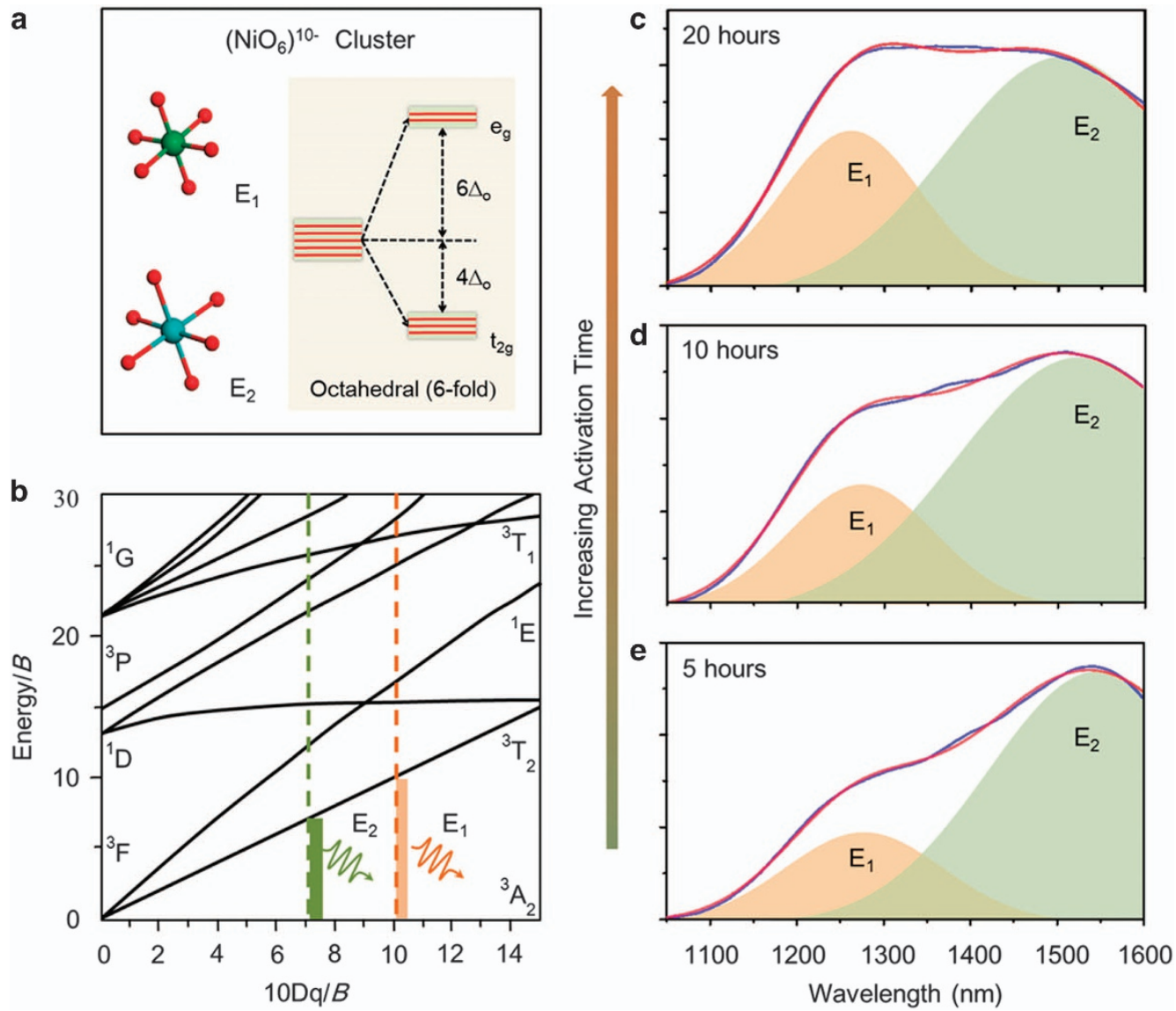

Figure 4 Mesoscale structure-mediated tunable NIR emission of the $\mathrm{Ni}^{2+}$-doped glass-ceramic composite. (a) Schematic representation indicating the configurations of the $\left(\mathrm{NiO}_{6}\right)^{10-}$ octahedron and the crystal-field splitting of the $3 d$ orbitals of $\mathrm{Ni}^{2+}$ in octahedral coordination. (b) Tanabe-Sugano diagram; the full rectangles indicate the crystal field of $\mathrm{Ni}^{2+}$ corresponding to the luminescence centers $\mathrm{E}_{1}$ and $\mathrm{E}_{2}$. (c-e) Fitted NIR luminescence spectra (the blue curves show the measured data, and the red curves represent the corresponding best fits). The bottom to top panels show the $\mathrm{Ni}^{2+}$-doped glass-ceramic composite activated by increasing annealing time from 5 to 10 and $20 \mathrm{~h}$ at $750{ }^{\circ} \mathrm{C}$. The deconvoluted peaks show the emission centers $\mathrm{E}_{1}$ (orange) and $\mathrm{E}_{2}$ (green). NIR, near-infrared. 
Mesoscale engineering for tunable luminescence

$\mathrm{Ni}^{2+}$ doping. The presence of a rich mesoscale structure in the glassceramic composite may increase the chance of obtaining optically active dopants, and site-to-site variations offer unique opportunities for inhomogeneous spectral emission bandwidth broadening. To verify this suggestion, $\mathrm{Ni}^{2+}$ ions were chosen as the probing dopant, taking into account its fundamental role in the active photonics. ${ }^{21,22}$ The $\mathrm{Ni}^{2+}$ doping level was $0.15 \mathrm{~mol} . \%$, and the doped glass-ceramic composite was produced by the same thermal treatment as the host LTAS glass, that is, annealing at $750{ }^{\circ} \mathrm{C}$ and for $5 \mathrm{~h}$.

Figure $3 \mathrm{a}$ shows the representative absorption spectrum of the $\mathrm{Ni}^{2+}$-doped glass-ceramic composite. Characteristic absorption peaks ${ }^{3} A_{2}(F) \rightarrow{ }^{3} T_{2}(F)(\lambda=1270 \mathrm{~nm})$ and ${ }^{3} A_{2}(F) \rightarrow{ }^{3} T_{1}(F)(\lambda=716 \mathrm{~nm})$, corresponding to electronic transitions in $\left(\mathrm{NiO}_{6}\right) 10^{-}$clusters, are observed. $^{23,24}$ Importantly, we observed an ultra-broadband NIR luminescence with the highest full-width at half-maximum of $\sim 400 \mathrm{~nm}$ in the glass-ceramic composite (Figure 3b). Interestingly, the shape of the steady-state emission is highly sensitive to the excitation wavelength (Figure $3 \mathrm{~b}$ and Supplementary Figure S7). The examination of the decay process shows that the decay times cannot be simply fit to the exponential decay equation (Figure 3c). Moreover, the steady-state excitation measurements show a spectral shift when changing the detection wavelength (Figure 3d). All these results provide solid proof of the remarkable NIR emission broadening originating from the inhomogeneous glass-ceramic structure, in contrast to the reference glass-ceramic composite $\mathrm{Ni}^{2+}$-doped $\mathrm{Ga}_{2} \mathrm{O}_{3}$, for which only negligible inhomogeneous broadening is observed (Supplementary Figures S8 and S9).

The structure of the $\mathrm{Ni}^{2+}$ doped glass-ceramic composite was studied by XANES measurements of the active centers. As shown in Figure 3e, the XANES spectrum of the Ni dopant in the glass-ceramic composite resembles that of $\mathrm{NiO}$, suggesting that the average first-shell coordination number of $\mathrm{Ni}^{2+}$ is approximately eight, which is consistent with the optical analysis presented above. The XANES spectra of the Ni-O shell in $R$-space show notable extension, strongly indicating the existence of site-to-site variation of $\mathrm{Ni}^{2+}$ in the glass-ceramic composite (Figure $3 \mathrm{f}$ and Supplementary Figure S10).
Origin of luminescence. Another distinct advantage of the unique mesoscale structure in the multiphase $\mathrm{Ni}^{2+}$-doped glass-ceramic composite is that it can also facilitate effective management of the emission output. In a further set of experiments, we synthesized samples using variable annealing times of $0,5,10$ and $20 \mathrm{~h}$ at a temperature $T=750{ }^{\circ} \mathrm{C}$. The fully glassy sample shows negligible emission in the NIR spectral region (Supplementary Figure S11). By inducing growth of the nanocrystals in the glass, the emission not only shows remarkable intensity enhancement but also changes its spectral band shape (Figure $4 \mathrm{c}-\mathrm{e}$ ). The contribution of $\mathrm{Ni}^{2+}$ from the glassy phase to the radiative transitions is negligible. Distinctive bands of $\left(\mathrm{NiO}_{6}\right) 10^{-}$active units in $\mathrm{LiTaO}_{3}$ and $\mathrm{LiAlSi}_{2} \mathrm{O}_{6}$ crystalline nanophases were obtained by deconvoluting the emission spectra, as indicated in Figure 4c-e. To further assign the observed emission bands, we performed a ligand-field theory analysis of the electronic transitions in $\left(\mathrm{NiO}_{6}\right) 10^{-}$clusters (Figure $4 \mathrm{a}$ and $\mathrm{b}$ ). The electrostatic field produced by the six ligands, for an octahedrally coordinated unit, can be expressed by the potential $V_{\text {oct }}$ according to equation (1): ${ }^{25,26}$

$$
V_{\text {oct }}=\frac{6 Z_{L e}}{R}+\frac{35 Z_{L e}}{4 R^{5}}\left(x^{4}+y^{4}+z^{4}-\frac{3}{4} r^{4}\right)
$$

where $\left(Z_{L e}\right)$ is the charge of the ligand separated by the distance $R$ from the cation, and $x, y, z$ and $r$ are the polar coordinates of the electrons. On the basis of this expression, the critical physical factor that determines the energy level configuration of $\left(\mathrm{NiO}_{6}\right)^{10-}$ clusters, that is, the crystal-field splitting parameter $\Delta_{\mathrm{o}}$, can be obtained according to equation (2):

$$
\Delta_{\mathrm{o}}=\frac{Q\left\langle r^{4}\right\rangle}{R^{5}}
$$

where $Q$ is a constant. The theoretical analysis indicates that $\Delta_{\mathrm{O}}$ is inversely proportional to the fifth power of the distance between the central cation and the surrounding ligands. According to the crystalfield splitting illustration of the $3 d$ orbitals of $\mathrm{Ni}^{2+}$ in the octahedral coordination state (Figure 4a), the large crystal-field splitting parameter $\Delta_{\mathrm{o}}$ directly leads to the enhancement of the energy gap between the ground state and excited states. Thus, it is believed that

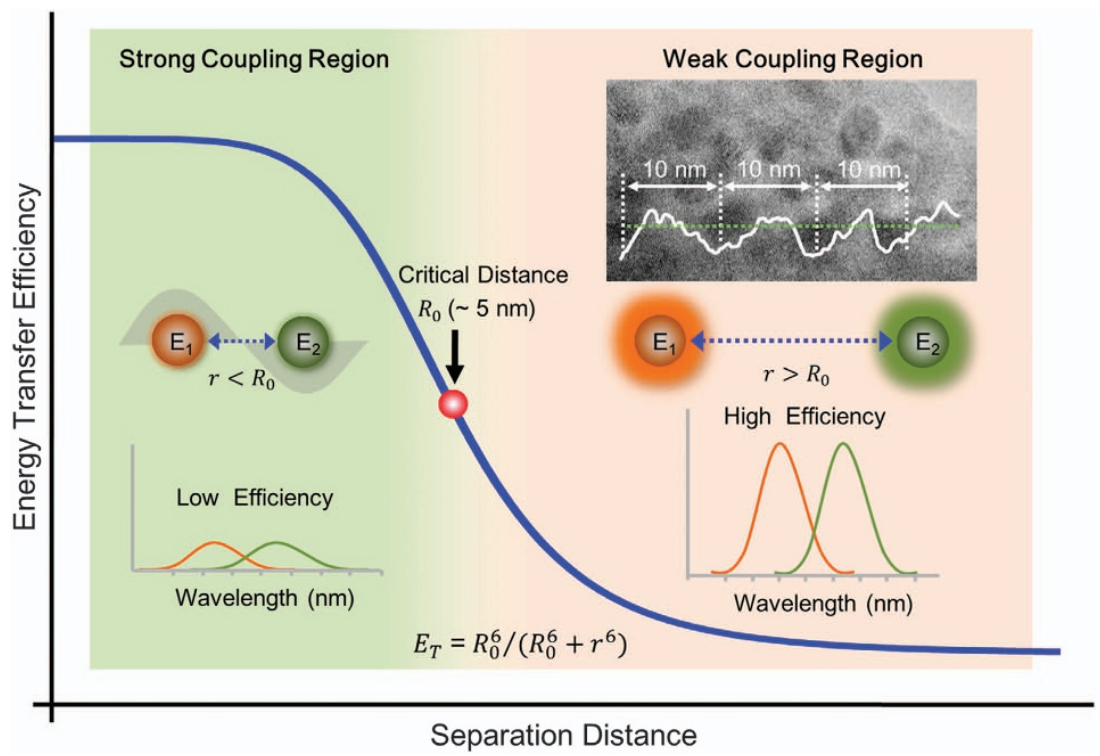

Figure 5 Mesoscale structure-mediated management of dopant-dopant interaction. Schematic illustration showing the dependence of the energy transfer process on the separation distance, $r$, between the two emission centers $E_{1}$ and $E_{2}$. The line profile in the TEM image indicates the contrast from the dotted line. 

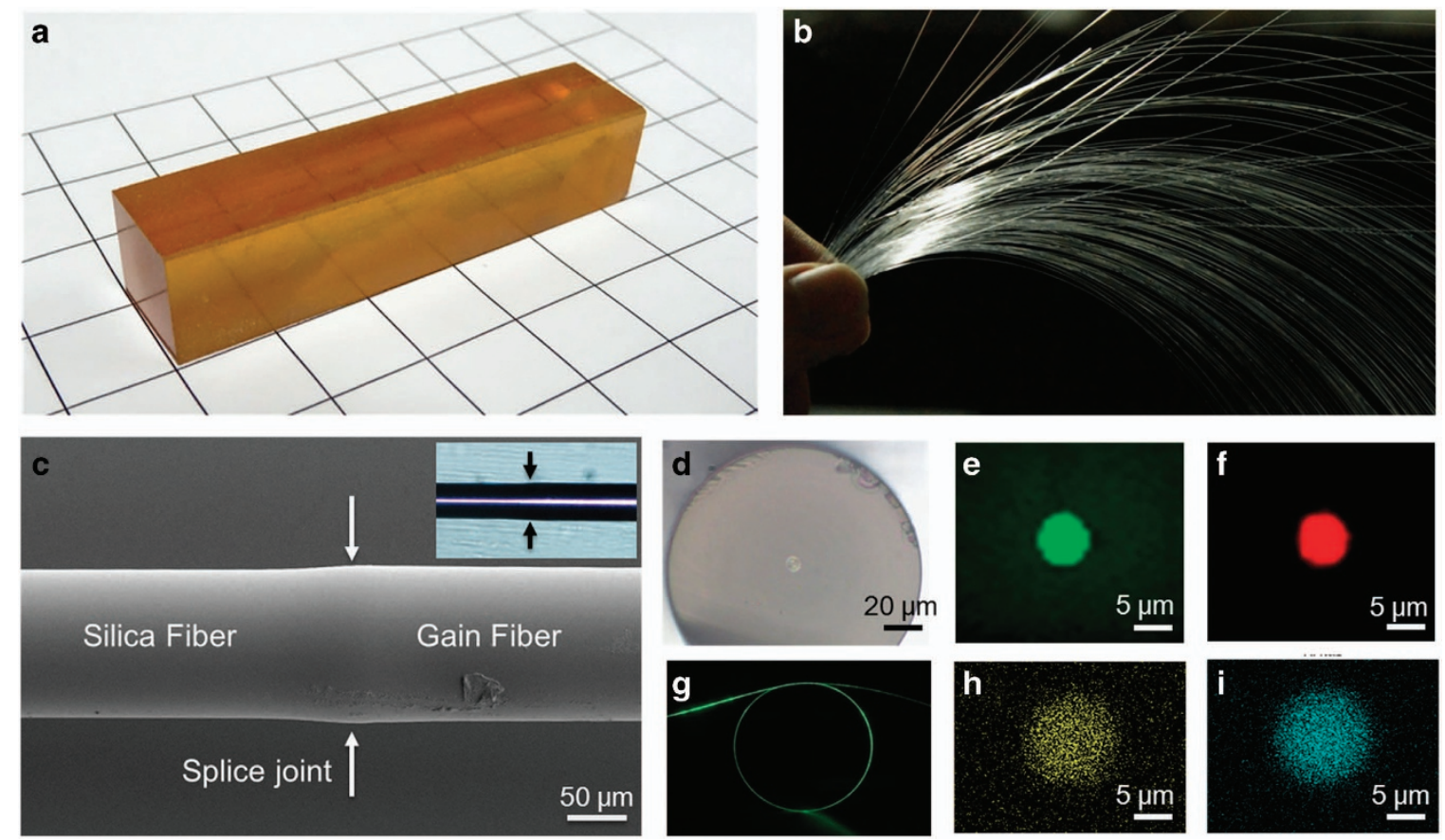

Figure 6 Photonic glass fiber. (a and b) Photographs of the starting bulk glass $\left(1 \times 1 \times 5.5 \mathrm{~cm}^{3}\right)$ and the drawn fibers. (c) SEM image of the splice joint between the commercial silica fiber (on the left of the joint) and the activated multiphase glass-ceramic composite gain fiber (on the right of the joint). The inset shows the corresponding optical micrograph. (d) Optical cross-section micrograph of the activated fiber. The core diameter is $10 \pm 1 \mu \mathrm{m}$, and the cladding diameter is $130 \pm 2 \mu \mathrm{m}$. (e and f) Raman mapping of the fingerprint peaks of $\mathrm{LiTaO}_{3}\left(593 \mathrm{~cm}^{-1}\right)$ and $\mathrm{LiAlSi}_{2} \mathrm{O}_{6}\left(486 \mathrm{~cm}^{-1}\right.$ ) units in the $\mathrm{core}$ region of the activated fiber. (g) Photograph of the activated fiber. (h and i) EDX mappings of Ta and $\mathrm{Al}$ elements in the core region of the activated fiber. EDX, energy-dispersive X-ray spectrometer; SEM, scanning electron microscope.

$\left(\mathrm{NiO}_{6}\right) 10^{-}$clusters will emit in the high-energy region of the NIR spectral range in the $\mathrm{LiAlSi}_{2} \mathrm{O}_{6}$ matrix with a tight framework (indicated as $\mathrm{E}_{1}$ in Figure 4) and in the low-energy part of the NIR region in the $\mathrm{LiTaO}_{3}$ host matrix, which has a relatively open structure (indicated as $\mathrm{E}_{2}$ in Figure 4). A kinetic Raman study shows that $\mathrm{LiTaO}_{3}$ nanocrystals are already formed within $5 \mathrm{~h}$ of the annealing, while it takes up to $20 \mathrm{~h}$ for the $\mathrm{LiAlSi}_{2} \mathrm{O}_{6}$ to fully grow (Supplementary Figure S12). Therefore, the intensity enhancement of the $\mathrm{E}_{1}$ band originating from $\left(\mathrm{NiO}_{6}\right) 10^{-}$in $\mathrm{LiAlSi}_{2} \mathrm{O}_{6}$, is rather weak with increasing annealing time, leading to the notable changes in the emission shape (Figure 4c-e).

In addition to the interesting dopant-host matrix interaction, the physical origin of the controllable emission output can also be attributed to the unique dopant-dopant interactions within the multiphase glass with the special mesoscale structure. As schematically shown in Figure 5, energy migration can occur between two different active sites of a material embedded in a host matrix. ${ }^{27-29}$ We assume that there is a contribution from an electric exchange to the energy migration between the emission centers $E_{1}$ and $E_{2}$ due to the overlapping orbitals. The energy transfer rate $K_{\mathrm{T}}$ and the efficiency $E_{\mathrm{T}}$ can be expressed according to equations (3) and (4):

$$
\begin{aligned}
& K T=\frac{1}{\tau D} \cdot\left(\frac{R_{0}}{r}\right)^{6} \\
& E T=\frac{R_{0}^{6}}{R_{0}^{6}+r^{6}}
\end{aligned}
$$

where $\tau_{\mathrm{D}}, R_{0}$ and $r$ are the donor lifetime, the critical distance and the separation distance, respectively. Dopants in a conventional homogeneous host matrix are in close physical proximity to each other, less than $3 \mathrm{~nm}$ at typical doping levels of $0.15 \mathrm{~mol} \%$. In this case, dopant interactions falls within the strong coupling region and the unexpected 'internal friction', such as the non-radiative energy transfers, prevails (Figure 5). It becomes extremely difficult to separately extract photons from the emission centers $\mathrm{E}_{1}$ and $\mathrm{E}_{2}$. Unlike in a homogeneous glass, the unique mesoscale heterogeneities present in the prepared glass-ceramic composite allow complete isolation of the emission centers $\mathrm{E}_{1}$ and $\mathrm{E}_{2}$ because of the notable increase in the separation distance, $\approx 10 \mathrm{~nm}$. This shifts the correlation state of the $\mathrm{E}_{1}-\mathrm{E}_{2}$ interaction to the weak coupling region (Figure 5). As a result, each dopant contributes to the emission output of the system, leading to a significant enhancement of the emission efficiency and a tunable spectrum shape. Importantly, the emission output with the highest full-width at half-maximum of approximately $480 \mathrm{~nm}$ and an extremely flat spectral shape covering the entire $O, E, S, C$ and $L$ telecommunication bands $(\lambda=1260-1625 \mathrm{~nm})$ can be obtained (Figure 4c). To the best of our knowledge, this is the first time ever that simultaneous emission in the second and third telecommunication windows was achieved in a single-active material excited by a commercially available pumping source.

\section{Construction of optical fibers}

The newly developed $\mathrm{Ni}^{2+}$-doped glass-ceramic composite, with intriguing optical properties, was drawn into an optical fiber (see Experimental procedures). In a typical preform-to-fiber fabrication approach, a large size bulk glass with excellent optical quality is needed. As shown in Figure 6a, a macroscopic preform $\left(1 \times 1 \times 5.5 \mathrm{~cm}^{3}\right)$ was successfully prepared by thorough mixing and continuous bubbling processes. This specially designed glass has a high propensity for devitrification, which may potentially degrade the optical performance of the drawn fibers. To circumvent this issue, a 'molten-core' strategy was used to ensure the core homogeneity 
Table 1 Comparison of the optical properties between the constructed photonic glass-ceramic fiber and the typical commercial fibers

\begin{tabular}{|c|c|c|c|c|}
\hline Core material & Fiber preparation method & Emission center (nm) & Bandwidth (nm) & Ref. \\
\hline $\mathrm{LiTaO}_{3}$ and $\mathrm{LiAlSi}_{2} \mathrm{O}_{6}: \mathrm{Ni}^{2+}$ glass ceramics & Molten-core & $1250-1500$ & 480 & This work \\
\hline $\mathrm{TeO}_{2}: \mathrm{Er}^{3+}$ glass & Jacketing method & 1530 & 83 & 38 \\
\hline ZBLAN:Pr ${ }^{3+}$ & Jacketing method & 1310 & 100 & 39 \\
\hline $\mathrm{Y}-(\mathrm{Ga}, \mathrm{Al})_{2} \mathrm{O}_{3}: \mathrm{Ni}^{2+}$ glass ceramics & Rod-in-tube & 1250 & 250 & 40 \\
\hline YAG:Cr ${ }^{4+}$ crystal & Rod-in-tube & 1350 & 240 & 41 \\
\hline $\mathrm{SiO}_{2}-\mathrm{GeO}_{2}: \mathrm{Bi}$ glass & Chemical vapor deposition & 1100 & 200 & 42 \\
\hline
\end{tabular}
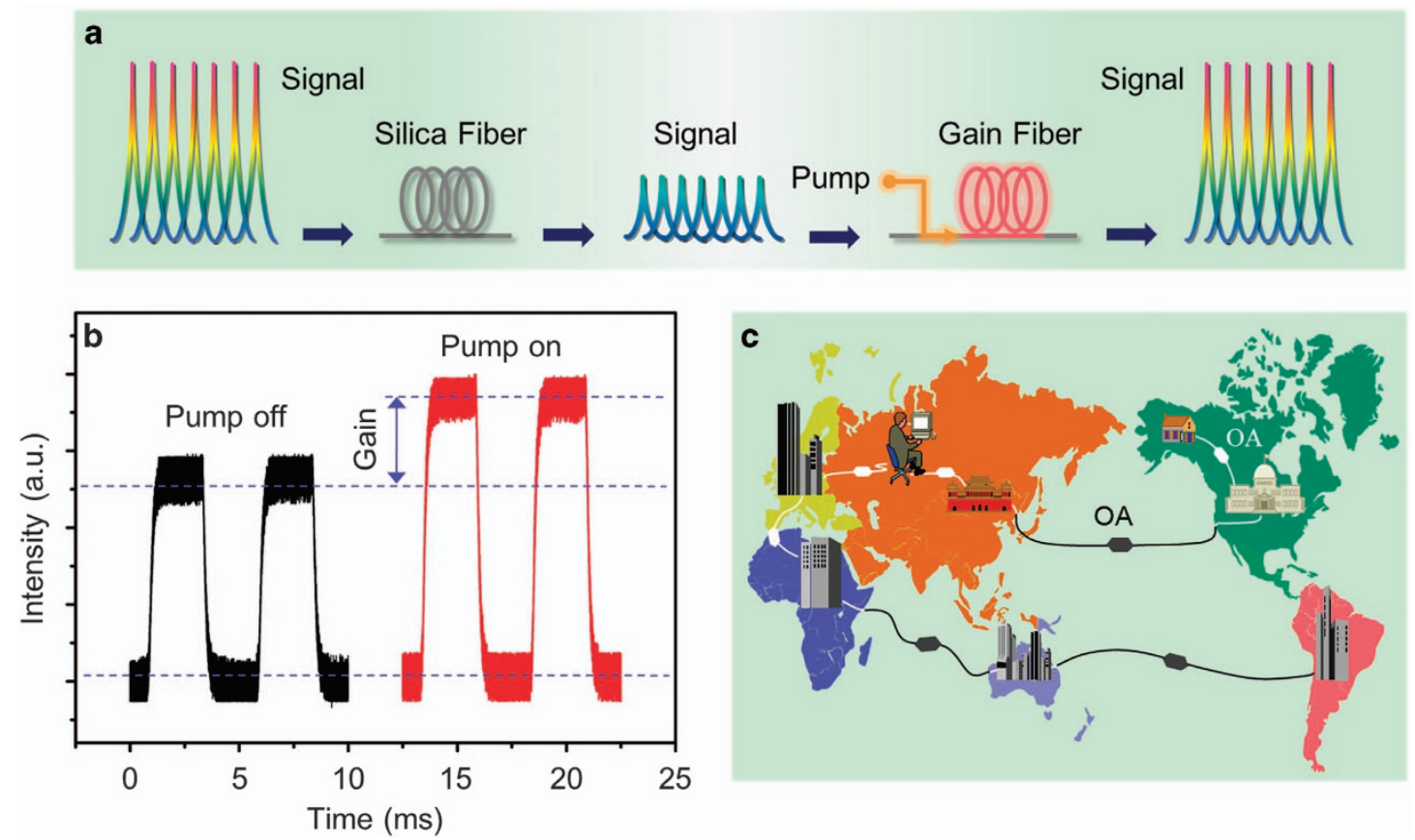

Figure 7 OA. (a) Schematic illustration of in situ optical signal amplification in a communication system. (b) Optical amplification properties at $\lambda=1300 \mathrm{~nm}$. (c) Schematic representation of an optical amplifier used for ultra-long distance telecommunication. OA, optical amplifier.

(Supplementary Figure S13). The preform was inserted into a silica cladding tube, and fibers were drawn at $1950^{\circ} \mathrm{C}$. The drawing temperature was kept above the melting point of the core phase, $T \approx 1550^{\circ} \mathrm{C}$. We believe that fluent floppy-mode network glass crosslinks with the cladding phase, resulting in the formation of strong interface bonding. Figure $6 \mathrm{~b}$ shows the photograph of the drawn fibers. The obtained fibers show good uniformity of density and the standard core-cladding configuration and can also be well connected to the commercial silica fibers (Figure $6 \mathrm{c}$ and d). Structural, compositional and optical analysis showed that the key functional units, that is, $\mathrm{LiTaO}_{3}$ and $\mathrm{LiAlSi}_{2} \mathrm{O}_{6}$ nanocrystals (Figure $6 \mathrm{e}-\mathrm{i}$ and Supplementary Figure S13), could be obtained during fiber activation by annealing at $T=800{ }^{\circ} \mathrm{C}$ for $20 \mathrm{~h}$. Importantly, the drawing process (Supplementary Figure S14) can prepare long fibers at commercially relevant speeds.

The optical properties of the typical active fibers are summarized in Table 1. The emission bandwidth of the $\mathrm{Ni}^{2+}$-doped glass-ceramic fiber extends the range that can be achieved with commercially available fibers. Furthermore, the prepared fiber shows potentially strong nonlinear effects (Supplementary Figure S15), which originate from the spectral modulation function of the precipitated $\mathrm{LiTaO}_{3}$ nanocrystals. Therefore, this novel fiber could also be applied as a multifunctional light source with a high level of integration.
It is believed that the excellent optical performance of the constructed fiber benefits from the proposed unique mesoscale engineering approach.

\section{Optical amplifier}

To examine the feasibility of the potential use of the glass-ceramic material in communication technology, a proof-of-principle device was constructed to measure the optical signal amplification performance. The test was conducted in a configuration resembling the conventional two-wave mixing geometry. Figure $7 \mathrm{~b}$ shows the optical amplification property at $\lambda=1300 \mathrm{~nm}$ with an excitation power of $\sim 1.1 \mathrm{~W}$. The oscilloscope image with and without an optical pump clearly indicates that the intensity of the modulated probe signal can be amplified by $\sim 40 \%$. This equals an optical gain of $1.4 \mathrm{~dB}$. The proposed principal optical amplifier device could potentially be embedded into a communication system and could support ultra-long distance telecommunication, for example, $\approx 14000 \mathrm{~km}$ from Beijing to Washington, by regenerating the attenuated optical signal (Figure $7 \mathrm{a}$ and c). Another key advantage of our new composite material is the extremely flat spectral shape and notable emission bandwidth, which allows for in situ amplification of an optical signal in a wide wavelength region covering the entire telecommunication windows. As is well known, traditional Erbium-doped optical 
amplifier can only provide limited bandwidth amplification $(\sim 11 \mathrm{THz}) .{ }^{30}$ In contrast, the $\mathrm{Ni}^{2+}$-doped glass-ceramic composite can potentially offer broad gain from 1140 to $1620 \mathrm{~nm}$ with a bandwidth of $\sim 78 \mathrm{THz}$, thus being promising for use in the nextgeneration super-capacity information transmission systems. As an added benefit, the profound extended emission of the constructed material is also highly beneficial for minimizing signal cross-saturation and cross talk in these modern systems. ${ }^{8}$

\section{CONCLUSIONS}

We have successfully demonstrated an effective way for tuning and controlling photon emission by manipulating mesoscale heterogeneities in a multicomponent-glass-ceramic composite. Unlike the conventionally used approach, which has achieved only limited possibilities for tailoring the spectral broadening, the inhomogeneous mesoscale structure engineering protocol presented in this paper allows broadening of the emission bandwidth up to $\sim 480 \mathrm{~nm}$, that is, two times larger than that with the conventional approach, $\sim 240 \mathrm{~nm}$. For the first time, simultaneous extension of the emission bandwidth and a flat spectral shape in a multicomponent-glassceramic composite have been demonstrated. We believe not only that our findings will provide major steps toward precise control of the dopant-dopant and the dopant-host matrix interactions on the mesoscale but also that the results offer exciting opportunities for the construction of next-generation composite and fibers, which are urgently needed in high-capacity telecommunication, remote sensing and defense applications. ${ }^{31-33}$ Furthermore, the understanding of and manipulation on the mesoscale could lead to new material functionalities, which could potentially be applied in engineering a variety of materials, such as ceramics, ${ }^{34}$ cements, ${ }^{35}$ organic dyes ${ }^{36}$ and other composites, ${ }^{37}$ where the mesoscale architecture becomes the typical microstructure of the applied system.

\section{CONFLICT OF INTEREST}

The authors declare no conflict of interest.

\section{ACKNOWLEDGEMENTS}

We thank Qiangbin Guo, Jiejie Chen and Binbin Zheng for help with the glass and fiber fabrications. We thank Wei Lin and Shichao Lv for helping to characterize the optical properties of the fiber. We gratefully acknowledge the financial support from the National Natural Science Foundation of China (grant 11474102 and 51202180), the National Science Fund for Excellent Young Scholars of China (grant 51622206), the Chinese Program for New Century Excellent Talents in University (grant NCET-13-0221), Guangdong Natural Science Funds for Distinguished Young Scholars (grant S2013050014549), Fundamental Research Funds for the Central University, the Scientific Research Foundation for Returned Overseas Chinese Scholars, the State Education Ministry, the Tip-top Scientific and Technical Innovative Youth Talents of Guangdong special support program (grant 2015TQ01C362) and the World Premier International Research Center Initiative (WPI), MEXT, Japan.

1 Weber, J. K. R., Felten, J. J., Cho, B. \& Nordine, P. C. Glass fibres of pure and erbium-or neodymium-doped yttria-alumina compositions. Nature 393, 769-771 (1998).

2 Dragic, P., Hawkins, T., Foy, P., Morris, S. \& Ballato, J. Sapphire-derived all-glass optical fibres. Nat. Photonics 6, 627-633 (2012).

3 Jackson, S. D. Towards high-power mid-infrared emission from a fibre laser. Nat. Photonics 6, 423-431 (2012).

4 Richardson, D. J. Filling the light pipe. Science 330, 327-328 (2010).

5 Bookey, H. T., Lousteau, J., Jha, A., Gayraud, N., Thomson, R. R., Psaila, N. D., Li, H. MacPherson, W. N., Barton, J. S. \& Kar, A. K. Multiple rare earth emissions in a multicore tellurite fiber with a single pump wavelength. Opt. Express 15, 17554-17561 (2007)
6 Labio, L. D., Lüthy, W., Romano, V., Sandoz, F. \& Feurer, T. Super broadband fluorescence fiber fabricated with granulated oxides. Opt. Lett. 33, 1050-1052 (2008).

7 Wang, F., Han, Y., Lim, C. S., Lu, Y. H., Wang, J., Xu, J., Chen, H. Y., Zhang, C., Hong, M. H. \& Liu, X. G. Simultaneous phase and size control of upconversion nanocrystals through lanthanide doping. Nature 463, 1061-1065 (2010).

8 Jha, A., Shen, S. \& Naftaly, M. Structure origin of spectral broadening of 1.5- $\mu \mathrm{m}$ emission in $\mathrm{Er}^{3+}$-doped tellurite glasses. Phys. Rev. B. 62, 6215-6227 (2000).

9 Im, W. B., George, N., Kurzman, J., Brinkley, S., Mikhailovsky, A., Hu, J., Chmelka, B. F., DenBaars, S. P. \& Seshadri, R. Efficient and colour-tunable oxyfluoride solid solution phosphors for solid-state white lighting. Adv. Mater. 23, 2300-2305 (2011).

10 Huang, P. Y., Kurasch, S., Alden, J. S., Shekhawat, A., Alemi, A. A., McEuen, P. L., Sethna, J. P., Kaiser, U. \& Muller, D. A. Imaging atomic rearrangements in two-dimensional silica glass: watching silica's dance. Science 342, 224-227 (2013).

11 Varshneya, A. K. Fundamentals of Inorganic Glasses, (Academic Press, 1994).

12 Andrew, P. \& Barnes, W. L. Förster energy transfer in an optical microcavity. Science 209, 785-788 (2000).

13 Wang, F., Deng, R., Wang, J., Wang, Q. X., Han, Y., Zhu, H. M., Chen, X. Y. \& Liu, X. G. Tuning upconversion through energy migration in core-shell nanoparticles. Nat. Mater. 10, 968-973 (2011).

14 Ketov, S. V., Sun, Y. H., Nachum, S., Lu, Z., Checchi, A., Beraldin, A. R., Bai, H. Y., Wang, W. H., Louzguine-Luzgin, D. V., Carpenter, M. A. \& Greer, A. L. Rejuvenation of metallic glasses by non-affine thermal strain. Nature 524, 200-203 (2015).

15 Fang, Z. J., Zheng, S. P., Peng, W. C., Zhang, H., Ma, Z. J., Zhou, S. F., Chen, D. P. \& Qiu, J. R. Fabrication and characterization of glass-ceramic fiber-containing $\mathrm{Cr}^{3+}$-doped $\mathrm{ZnAl}_{2} \mathrm{O}_{4}$ nanocrystals. J. Am. Ceram. Soc. 98, 2772-2775 (2015).

16 Kingery, W. D., Bowen, H. K. \& Uhlmann, D. R. Introduction to Ceramics, (John Wiley \& Sons, 1975).

17 Dargaud, O., Cormier, L., Menguy, N., Patriarche, G. \& Calas, G. Mesoscopic scale description of nucleation processes in glasses. Appl. Phys. Lett. 99, 1-3 (2011).

18 Karpov, V. G. \& Oxtoby, D. W. Nucleation in disordered systems. Phys. Rev. B. 54, 9734-9745 (1996).

19 Raptis, C. Assignment and temperature dependence of the Raman modes of $\mathrm{LiTaO}_{3}$ studied over the ferroelectric and paraelectric phases. Phys. Rev. B. 38, 10007-10019 (1988)

20 Sharma, S. K. \& Simons, B. Raman study of crystalline polymorphs and glasses of spodumene composition quenched from various pressures. Am. Mineral. 66 , 118-126 (1981).

21 Johnson, L. F., Dietz, R. E. \& Guggenheim, H. J. Optical maser oscillation from $\mathrm{Ni}^{2+}$ in $\mathrm{MgF}_{2}$ involving simultaneous emission of phonons. Phys. Rev. Lett. 11, 318-320 (1963).

22 Zhou, S. F., Li, C. Y., Yang, G., Bi, G., Xu, B. B., Hong, Z. L., Miura, K., Hirao, K. \& Qiu, J. R. Self-limited nanocrystallization-mediated activation of semiconductor nanocrystal in an amorphous solid. Adv. Funct. Mater. 23, 5436-5443 (2013).

23 Zhou, S. F., Jiang, N., Miura, K., Tanabe, S., Shimizu, M., Sakakura, M., Shimotsuma, Y., Nishi, M., Qiu, J. R. \& Hirao, K. Simultaneous tailoring of phase evolution and dopant distribution in the glassy phase for controllable luminescence. J. Am. Chem. Soc. 132, 17945-17952 (2010).

24 Liusar, R., Casarrubios, M., Barandiarán, Z. \& Seijo, L. Ab initio model potentia calculations on the electronic spectrum of $\mathrm{Ni}^{2+}$-doped $\mathrm{MgO}$ including correlation, spin-orbit and embedding effects. J. Chem. Phys. 105, 5321-5330 (1996).

25 Tanabe, Y. \& Sugano, S. On the absorption spectra of complexions II. J. Phys. Soc. Jpn. 9, 766-779 (1954).

26 Burns, R. G. Mineralogical Applications of Crystal Field Theory, (Cambridge University Press, 1993).

27 Achermann, M., Petruska, M. A., Kos, S., Smith, D. L., Koleske, D. D. \& Klimov, V. I. Energy-transfer pumping of semiconductor nanocrystals using an epitaxial quantum well. Nature 429, 642-646 (2004).

28 Chanyawadee, S., Lagoudakis, P. G., Harley, R. T., Charlton, M. D. B., Talapin, D. V., Huang, H. W. \& Lin, C. Increased color-conversion efficiency in hybrid light-emitting diodes utilizing non-radiative energy transfer. Adv. Mater. 22, 602-606 (2010).

29 Förster, T. 10th spiers memorial lecture transfer mechanisms of electronic excitation. Discuss. Farad. Soc. 27, 7-17 (1959).

30 Vardeny, Z. V. Telecommunication: a boost for fiber optics. Nature 416 489-491 (2002).

31 Zhou, S. F., Guo, Q. B., Inoue, H., Ye, Q., Masuno, A., Zheng, B. B., Yu, Y. Z. \& Qiu, J. R. Topological engineering of glass for modulating chemical state of dopants. Adv. Mater. 26, 7966-7972 (2014).

32 Yamada, M., Ono, H. \& Ohishi, Y. Low-noise, broadband $\mathrm{Er}^{3+}$-doped silica fibre amplifiers. Electron. Lett. 34, 1490-1491 (1998).

33 Tanabe, S., Hayash, H. \& Hanada, T. Improved fluorescence from Tm-Ho- and Tm-Ho-Eu-codoped transparent $\mathrm{PbF}_{2}$ glass-ceramics for $\mathrm{s}^{+}$-band amplifiers. J. Am. Ceram. Soc. 85, 839-843 (2002).

34 Barriocanal, J. G., Calzada, A. R., Varela, M., Sefrioui, Z., Lborra, E., Leon, C., Pennycook, S. J. \& Santamaria, J. Colossal ionic conductivity at interfaces of epitaxial $\mathrm{ZrO}_{2}: \mathrm{Y}_{2} \mathrm{O}_{3} / \mathrm{SrTiO}_{3}$ heterostructures. Science 321, 676-670 (2008).

35 Yip, S. \& Short, M. P. Multiscale materials modelling at the mesoscale. Nat. Mater. 12 774-777 (2013).

36 Poelking, C., Tietze, M., Elschner, C., Olthof, S., Hertel, D., Baumeier, B., Würthner, F., Meerholz, K., Leo, K. \& Andrienko, D. Impact of mesoscale order on open-circuit voltage in organic solar cells. Nat. Mater. 14, 434-439 (2015).

37 Zhou, S. F., Zheng, B. B., Shimotsuma, Y., Lu, Y. H., Guo, Q. B., Nishi, M., Shimizu, M., Miura, K., Hirao, K. \& Qiu, J. R. Heterogeneous-surface-mediated crystallization control. NPG Asia Mater. 8, e245 (2016). 
38 Mori, A., Kobayashi, K., Yamada, M., Kanamori, T., Oikawa, K., Nishida, Y. \& Ohishi, Y. Low noise broadband tellurite-based $\mathrm{Er}^{3+}$-doped fibre amplifiers. Electron. Lett. 34, 887-888 (1998).

39 Ohishi, Y., Kanamori, T., Kitagawa, T. \& Takahashi, S. $\mathrm{Pr}^{3+}$-doped fluoride fiber amplifier operating at $1.31 \mu \mathrm{m}$. Opt. Lett. 16, 1747-1749 (1991).

40 Samson, B. N., Pinckney, L. R., Wang, J., Beall, G. H. \& Borrelli, N. F. Nickel-doped nanocrystalline glass-ceramic fiber. Opt. Lett. 27, 1309-1311 (2002).

41 Lo, C. Y., Huang, K. Y., Chen, J. C., Tu, S. Y. \& Huang, S. L. Glass-clad Cr ${ }^{4+}$ :YAG crystal fiber for the generation of super wideband amplified spontaneous emission. Opt. Lett. 29, 439-441 (2004).

42 Dvoyrin, V. V., Mashinsky, V. M., Bulatov, L. I., Bufetov, I. A., Shubin, A. V., Melkumov, M. A., Kustov, E. F., Dianov, E. M., Umnikov, A., Khopin, V. F., Yashkov, M. V. \& Guryanov, A. N. Bismuth-doped-glass optical fibers-a new active medium for lasers and amplifiers. Opt. Lett. 31, 2966-2968 (2006). (c) (i)

This work is licensed under a Creative Commons Attribution 4.0 International License. The images or other third party material in this article are included in the article's Creative Commons license, unless indicated otherwise in the credit line; if the material is not included under the Creative Commons license, users will need to obtain permission from the license holder to reproduce the material. To view a copy of this license, visit http:// creativecommons.org/licenses/by/4.0/

(C) The Author(s) 2016

Supplementary Information accompanies the paper on the NPG Asia Materials website (http://www.nature.com/am) 